\title{
PIRAÍ DA SERRA - PROPOSTA DE NOVA UNIDADE DE CONSERVAÇÃO NOS CAMPOS GERAIS DO PARANÁ
}

\section{PIRAÍ DA SERRA - PROPOSAL FOR A NEW PRESERVATION UNIT IN THE CAMPOS GERAIS REGION OF THE STATE OF PARANÁ, IN SOUTHERN BRAZIL}

\author{
Mário Sérgio de Melo ${ }^{1 *}$, Lindon Fonseca Matias', \\ Gilson Burigo Guimarães ${ }^{1}$, Gilson Campos Ferreira da Cruz ${ }^{1}$, \\ Ivana de Freitas Barbola ${ }^{2}$, Ana Maria Gealh², Rosemeri Segecin Moro², \\ Cristina Lúcia Santana Costa Ayub $^{2}$, Paulo Rogério Moro ${ }^{3}$, \\ Jasmine Cardozo Moreira ${ }^{4}$ \\ 1* Autor para contato: Universidade Estadual de Ponta Grossa - UEPG, Campus em \\ Uvaranas, Departamento de Geociências, Ponta Grossa, PR, Brasil; \\ e-mail:msmelo@uepg.br \\ 2 Universidade Estadual de Ponta Grossa - UEPG, Campus em Uvaranas, Departamento \\ de Biologia Geral, Ponta Grossa, PR, Brasil \\ 3 Universidade Estadual de Ponta Grossa - UEPG, Campus Central, Departamento de \\ Métodos e Técnicas de Ensino, Ponta Grossa, PR, Brasil \\ 4 Universidade Estadual de Ponta Grossa - UEPG, Campus Central, Departamento de \\ Turismo, Ponta Grossa, PR, Brasil
}

Recebido para publicação em 13/10/04 Aceito para publicação em 10/03/05

\section{RESUMO}

Piraí da Serra é uma denominação local de parte dos Campos Gerais do Paraná que se destaca pelo contrastante relevo de topos aplainados com campos e rios encaixados em canyons paralelos na direção NW-SE, onde ocorre floresta de araucária. São também comuns sítios arqueológicos de populações indígenas pré-históricas que utilizavam as passagens naturais para seus deslocamentos entre os planaltos e o litoral. Os Campos Gerais estendem-se por $11.761,41 \mathrm{~km}^{2}$. Unidades de conservação já implantadas somam 4.867 ha, correspondentes a $0,41 \%$ da região. Além de ser muito pequena, essa área já protegida abrange algumas porções muito alteradas, e é marcante a escassez de conhecimentos sobre os fatores bióticos e abióticos dessa grande região natural, que vem sofrendo rápida e profunda transformação pela expansão de florestamentos com Pinus, agricultura e pecuária intensivas. Estudos interdisciplinares recentes sobre os Campos Gerais foram realizados por pesquisadores da UEPG visando a caracterização e gestão de seu patrimônio natural. Eles apontaram a região de Piraí da Serra, com cerca de 150 km², como extensa e preservada área contínua, 
onde a notável fisiografia condiciona complexa interdigitação de ecossistemas, e determina estrutura fundiária que favorece a preservação e as futuras negociações para implantação de nova unidade de conservação.

Palavras-chave: Campos Gerais do Paraná, unidade de conservação, bioma campos sulinos.

\begin{abstract}
"Piraí da Serra" is a local denomination for the "Campos Gerais", a natural grassland region of the State of Paraná, in Southern Brazil. The relief presents plateaus, with grassy open fields contrasting with rivers in deep canyons. Isolated groves and riparian araucaria forests are common in this region. The area contains several archaeological sites of prehistorical indigenous populations that used the natural passes for displacements between the plateaus and the coast. The "Campos Gerais” region extends for $11,761.41 \mathrm{~km}^{2}$, but already implanted preservation units totalize a mere $0.41 \%$ of the territory. Besides being very small, these protected areas embrace some very damaged portions, and the knowledge about the abiotic and biotic factors of this large natural region is scarce. In addition, the odds against preservation are increasing because of the forestation with exotic species and the expansion of agriculture and cattle raising. Studies concerning the natural patrimony of the "Campos Gerais" revealed that the "Piraí da Serra” region, with about 150 $\mathrm{km}^{2}$, is a widespread and continuous preserved area where the singular relief favors a complex coexistence of ecosystems and where the landownership structure favors the preservation of nature. Such characteristics make this area suitable for a new preservation unit in the "Campos Gerais" region.
\end{abstract}

Key words: “Campos Gerais do Paraná”, preservation units, Southern - Brazilian grassland biome.

\section{Introdução}

Entre 2000 e 2003 pesquisadores da UEPG Universidade Estadual de Ponta Grossa - realizaram estudos visando a caracterização e a gestão do patrimônio natural dos Campos Gerais do Paraná (UEPG 2003). Tais estudos tiveram caráter interdisciplinar, e seu objetivo final foi contribuir para reafirmar a opção por atividades econômicas sustentáveis, com incremento da consciência ambiental, da identidade regional e da cidadania.

A região dos Campos Gerais, definida por Maack (1950) como zona fitogeográfica situada na borda do Segundo Planalto Paranaense, onde dominam campos com capões e matas ripárias de floresta de araucária subordinados, destaca-se por substrato rochoso e relevo singulares, que condicionam as formações vegetais presentes. O relevo é marcado pela Escarpa Devoniana, degrau topográfico localmente com até mais de $400 \mathrm{~m}$ de desnível, e pela presença de muitos rios encaixados em canyons paralelos na direção NW-SE, controlados por um dos mais notáveis exemplos mundiais de enxame de diques de rochas ígneas intrusivas, de idade mesozóica. Sucedem-se no relevo escarpamentos, canyons profundos e topos relativamente aplainados, com freqüentes exposições do substrato rochoso de arenitos da Formação Furnas, o que controla abruptos contrastes, gerando as con- 
dições para a coexistência de múltiplos micro-ecossistemas, ainda praticamente desconhecidos. Neles é possível encontrar remanescentes de rica flora endêmica e de espécies animais ameaçadas de extinção (suçuarana, lobo-guará, jaguatirica, gralha-azul, harpia ou gavião-real, gavião-caracoleiro, entre outras). Os arenitos, por sua vez, tendem a formar lapas que constituem abrigos naturais que muitas vezes contêm sítios arqueológicos de populações indígenas pré-históricas que utilizavam as passagens naturais da região para seus deslocamentos entre os planaltos e o litoral.

Os limites originais dos Campos Gerais do Paraná compreendem parte de 22 municípios da região centro-leste do Estado do Paraná, estendendo-se por 11.761,41 ha (Figura 1). Nessa área, quatro parques estaduais (Vila Velha, Guartelá, Monge, Cerrado) e uma floresta estadual (Passa Dois) já implantados somam 4.867 ha, correspondentes a 0,41\% da região dos Campos Gerais. Cerca de uma dezena de RPPN's - Reservas Particulares do Patrimônio Natural - federais e estaduais somam mais 5.080 ha (UEPG, 2003). Já a APA - Área de Proteção Ambiental - da Escarpa Devoniana, com 392.363,38 ha, apesar de criada por legislação de 1992, ainda não dispõe de zoneamento nem de plano de manejo implantados.
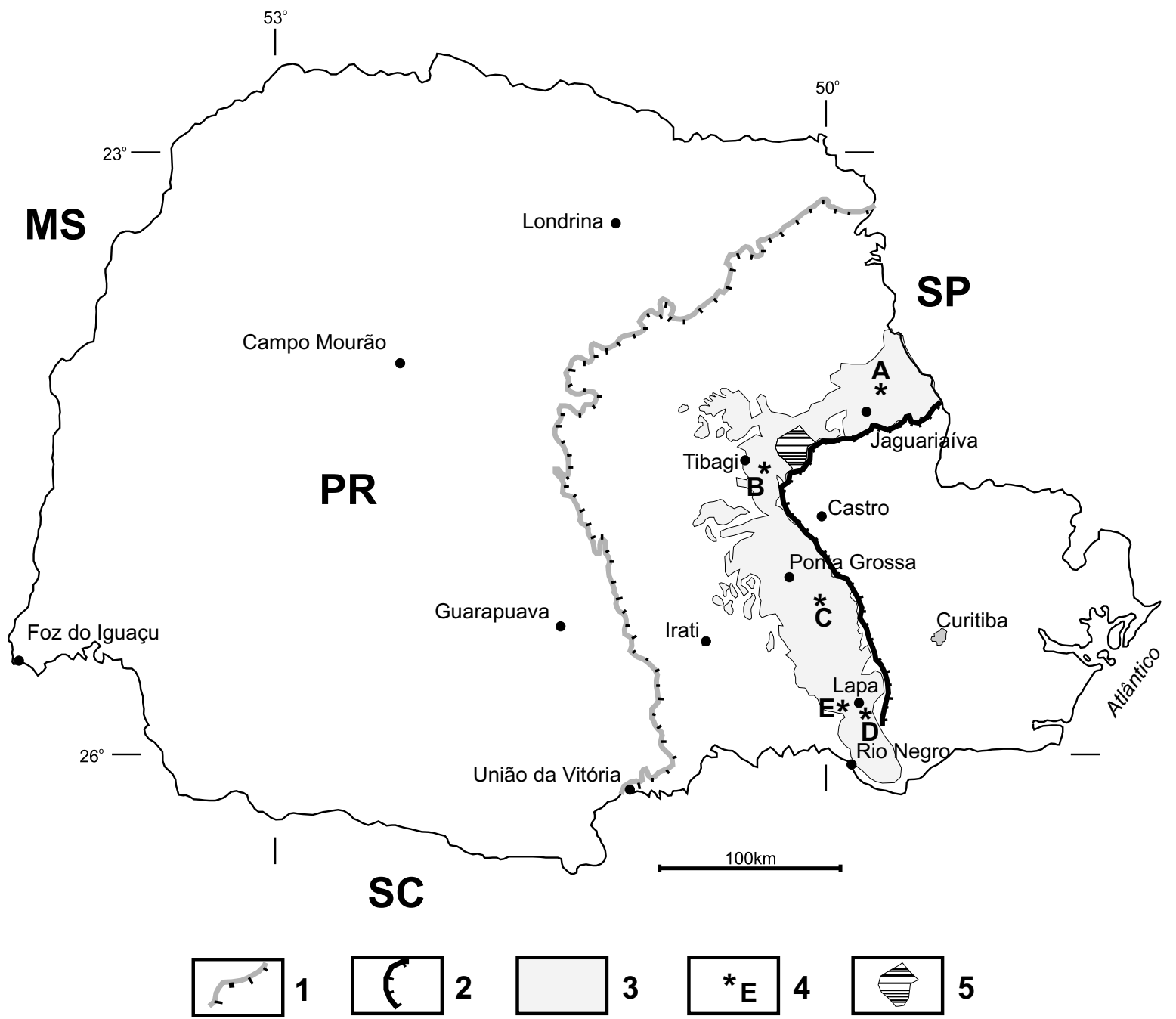

Figura 1 - Localização da região de Piraí da Serra nos Campos Gerais do Paraná. 1) Escarpa da Serra Geral; 2) Escarpa Devoniana; 3) Campos Gerais do Paraná; 4: unidades de conservação já implantadas - A: Parque Estadual do Cerrado; B: Parque Estadual do Guartelá; C: Parque Estadual de Vila Velha; D: Parque Estadual do Monge; E: Floresta Estadual do Passa Dois; 5) Área de Piraí da Serra. 
Além de muito pequena, a área efetivamente já protegida nos Campos Gerais abrange algumas porções muito alteradas, como se observa principalmente nos parques estaduais do Monge e de Vila Velha. Além disso, é marcante a escassez de conhecimentos sobre os fatores bióticos e abióticos dessa grande região natural, que vem sofrendo rápida e profunda transformação pela expansão de florestamentos com Pinus, agricultura e pecuária intensivas.

Nesse contexto, um dos resultados dos estudos realizados foi a proposição de áreas prioritárias para novas unidades de conservação, que venham a proteger o patrimônio natural dos Campos Gerais, e dar suporte a atividades de pesquisa, ecoturismo e Educação Ambiental. Dentre quatro áreas selecionadas com base em critérios de relevância do patrimônio natural e seu estado de preservação, destaca-se a região de Piraí da Serra (Figuras 1 e 2), situada dentro dos limites da APA da Escarpa Devoniana. Os dados resultantes dos primeiros levantamentos nessa área são aqui apresentados, sugerindo-se que estudos complementares de detalhe venham viabilizar a efetiva implantação da nova unidade de conservação.

\section{Métodos}

Os estudos que conduziram à proposição da criação da unidade de conservação de Piraí da Serra foram realizados na região dos Campos Gerais como um todo, compreendendo no total mais de $11000 \mathrm{~km}^{2}$, na qual a área proposta foi considerada prioritária. A metodologia adotada envolveu as seguintes áreas e respectivos procedimentos:

a) Geologia: mapeamento (escala 1:250.000) dos tipos de rochas e estruturas geológicas, e a análise de sua relação com os fatores abióticos e bióticos; inventário das seções-tipo de unidades rochosas; estudo de processos intempéricos e sua influência na evolução de formas de relevo; apoio do IGc-USP nas análises petrográficas e mineralógicas (microscopia ótica, microscopia eletrônica de varredura, espectrometria de energia dispersiva, difratometria de raios $\mathrm{X}$ ); uso de mapas preexistentes (MINEROPAR 2001), fotografias aéreas 1:70.000 (DGTC 1962/1963) e levantamentos de campo;

b) Geomorfologia: mapeamento (escala 1:250.000) de feições relevantes e sistemas de relevo, para correlação com os fatores abióticos e bióticos; uso de fotografias aéreas 1:70.000 (DGTC 1962/ 1963);

c) Pedologia: compilação (escala 1:250.000) dos tipos de solo a partir das cartas de solos da EMBRAPA (2002);

d) Clima: caracterização do clima dos Campos Gerais tendo como base as Cartas Climáticas do Estado do Paraná (IAPAR 1994 e 2000), compreendendo o levantamento de dados de precipitação, ventos, temperatura, insolação e umidade relativa do ar;

e) Vegetação: levantamento de área-piloto próxima a Ponta Grossa, visando definir critérios de aplicação regional; os trabalhos constaram de fotointerpretação, na escala 1:65.000, e metodologia de Avaliação Ecológica Rápida (Sobrevilla \& Bath 1992); a terminologia e conceituação seguem a Classificação da Vegetação Brasileira, de Veloso et al. (1991); as diretrizes para mapeamento em escala média (1:100.000) constam do Manual Técnico da Vegetação, do IBGE (1992);

f) Entomofauna: caracterização da entomofauna dos Campos Gerais, organização de coleção entomológica, avaliação da diversidade, abundância relativa e atividade sazonal de grupos de insetos e identificação de espécies potencialmente bioindicadoras de ambientes degradados; foram selecionados quatro locais, nos quais foram feitas coletas diurnas mensais, e instalados diversos tipos de armadilhas;

g) Ictiofauna: levantamento da ictiofauna nativa dos Campos Gerais a partir de capturas mensais em quatro estações de coleta, no período de maio de 2001 a abril de 2002; o esforço de pesca foi de 24 horas, com despescas a cada 12 horas (noturno e diurno); foi analisada a ocorrência, distribuição, regime alimentar e análise histológica das gônadas;

h) Mastofauna e avifauna: caracterização da região dos Campos Gerais somente a partir da compilação e análise de dados disponíveis na bibliografia específica;

i) Arqueologia: compilação e análise bibliográfica, produzindo-se uma síntese regional, e o levantamento de novos sítios, que compreendeu as seguintes 
etapas: fotointerpretação (fotos aéreas do DGTC de 1962/1963, escala 1:70.000 e do ITC-PR de 1980, escala 1:25.000); levantamentos de campo, incluindo topografia e localização de sítios arqueológicos, registro fotográfico do abrigo e das pinturas rupestres, elaboração de ficha cadastral para sítios arqueológicos com pinturas rupestres, documentação, análise e estudo das pinturas rupestres através de imagens digitalizadas;

j) Uso e ocupação da terra: mapeamento (escala 1:250.000) por meio de técnicas de sensoriamento remoto com base no software ArcView GIS Image Analysis (ESRI 2000), para processamento digital e classificação das imagens; foram utilizadas duas imagens digitais multiespectrais do satélite LANDSAT 7, sensor ETM+, órbita/ponto 221/77 e 221/78, passagem de 08/12/2000, para obtenção de um mosaico de imagens da região, em composições coloridas; após a etapa de georreferenciamento, as imagens foram submetidas às técnicas de classificação não-supervisionada e supervisionada, com apoio em trabalhos de campo e levantamento bibliográfico;

k) Turismo em áreas naturais: levantamento do potencial turístico, através de inventário e diagnóstico de atrativos;

l) Educação Ambiental; diagnóstico das atividades de Educação Ambiental desenvolvidas na rede escolar de cidades da região dos Campos Gerais, a partir de levantamentos durante realização do seminário “Áreas do Conhecimento”, na Universidade do Professor, em Faxinal do Céu (Moro, 2002); na continuidade, foram realizados seminários em parceria com o Núcleo Regional de Educação e secretarias de educação de alguns municípios, para proposição de atividades de Educação Ambiental;

m) Inventário dos sítios naturais e arqueológicos: com base nos levantamentos bibliográficos realizados (incluindo dados do IAP - Instituto Ambiental do Paraná - e prefeituras municipais, disponíveis em documentos impressos e na internet), interpretação de imagens de satélite e fotografias aéreas e levantamentos de campo, foi elaborado inventário com os seguintes dados: designação do sítio, município(s) de localização, coordenadas UTM, tipos principais de atrativos (rochas, relevo, hidrografia, flora, fauna, arqueologia), usos atuais (caminhadas, esportes na natureza, pesquisas, Educação Ambiental, excursões científicas, hotéis-fazenda, peregrinação) e impactos observados (erosão, queimadas, depredação da flora, depredação da fauna, depredação de vestígios arqueológicos, detritos)

n) Base de dados georreferenciados: estruturação e construção de uma base de dados georreferenciados cujo objetivo é agrupar os dados, na forma gráfica (mapas, imagens de satélite, fotografias aéreas, fotografias convencionais) e na forma alfanumérica (dados descritivos, tabelas, relatórios), em um ambiente de geoprocessamento, utilizando o software ArcView GIS (ESRI, 2000), visando subsidiar futuros projetos de pesquisa na região.

\section{Resultados}

Os principais resultados obtidos até o momento, referentes aos estudos mencionados acima são:

a) Geologia: mapa geológico (escala 1:250.000); inventário das seções-tipo de unidades rochosas; aprofundamento do conhecimento dos processos intempéricos dos arenitos da região (Formação Furnas e Grupo Itararé). Esses resultados encontram-se em relatórios (UEPG 2003; Melo 2004) e artigos (Melo et al. 2003);

b) Geomorfologia: mapa (escala 1:250.000) de feições relevantes e sistemas de relevo (cristas, diques, falhas, fendas, lineamentos, furnas, lagoas, depressões, anfiteatros, escarpamentos, morros testemunhos, planícies aluviais, leques aluviais, relevo ruiniforme, sumidouros, ressurgências, cachoeiras, corredeiras, drenagem convergente, drenagem divergente, boçorocas); tipologia de formas de relevo utilizável na região para inventário do patrimônio natural (Melo et al. s.d.)

c) Pedologia: mapa (escala 1:250.000) dos tipos de solo (UEPG 2003);

d) Clima: cartogramas de precipitação, ventos, temperatura, insolação e umidade relativa do ar na região dos Campos Gerais (UEPG 2003);

e) Vegetação: caracterização dos tipos de formações vegetais da região dos Campos Gerais e mapeamento de área-piloto (Moro 2001; Moro et al. 2002);

f) Entomofauna: foi capturado um total de 18.291 exemplares de insetos nas quatro áreas estudadas, das ordens Diptera, Hymenoptera, Lepidoptera e 
Coleopetera. O estudo desses exemplares (identificação, riqueza, similaridade) permitiu estabelecer comparações acerca dos padrões gerais de diversidade e composição da fauna de insetos de áreas pertencentes ao domínio Campos Gerais (Nascimento et al. 2002);

g) Ictiofauna: foram coletados 2.756 exemplares de peixes, verificando-se a presença de três novas espécies endêmicas; observou-se que algumas espécies permanecem todo o ano em locais estritos e que outras migram, indicando a necessidade de conservação dos diferentes ambientes em um ecossistema, para que a biodiversidade seja assegurada (UEPG 2003);

h) Mastofauna e avifauna: os resultados da compilação e análise de dados disponíveis na bibliografia indicam a ocorrência de 159 espécies de aves e 49 espécies de mamíferos, sendo várias delas consideradas vulneráveis ou ameaçadas de extinção;

i) Arqueologia: foi realizado o cadastramento e levantamento de 28 sítios arqueológicos com pinturas rupestres (em sua grande maioria abrigos sob rocha), principalmente nos municípios de Sengés, Jaguariaíva, Piraí do Sul e Ponta Grossa; foram notados três tipos de categorias de representações, as figuras humanas e geométricas em menor quantidade, e as figuras de animais (principalmente cervídeos) em grande quantidade, atribuíveis à Tradição Planalto (Silva \& Melo 2002; Silva et al. 2001);

j) Uso e ocupação da terra: foi produzido mapa na escala 1:250.000 contendo as principais classes de uso e ocupação encontradas na região: áreas urbanas, agricultura, campos, matas, reflorestamento. A partir das imagens também foi produzida uma carta imagem, em escala 1:250.000, como importante instrumento para visualização e conhecimento do território (UEPG 2003);

k) Turismo em áreas naturais: foi elaborado inventário e diagnóstico de atrativos em áreas naturais e das unidades de conservação já implantadas na região dos Campos Gerais, apresentando-se proposta de dire-trizes para o ecoturismo (UEPG 2003);

l) Educação Ambiental; foi elaborado diagnóstico das atividades de Educação Ambiental desenvolvidas na rede escolar de cidades da região dos Campos Gerais (Moro, 2002); realizaram-se seminários para proposição de atividades de Educação Ambiental (UEPG 2003);

m) Inventário dos sítios naturais e arqueológicos: esses sítios foram catalogados a partir do levantamento de dados realizado na região estudada (Melo et al. 2002; UEPG 2003);

n) Base de dados georreferenciados: foram elaboradas bases de dados abrangendo os vinte e dois municípios da região dos Campos Gerais, que além dos dados produzidos no projeto, congregam outros oriundos do IBGE (2000) que dispõe, para cada município, de 1.080 variáveis sobre os temas: posição e extensão, características das pessoas, vida e risco de vida, educação, saúde, habitação, migração, participação política, estrutura empresarial, agropecuária, instituições financeiras, finanças públicas.

\section{A região de Piraí da Serra}

A região de Piraí da Serra situa-se na margem esquerda do Rio Fortaleza, entre o Ribeirão Cambará a montante e o Lajeado Grande a jusante (Figura 2). Compreende superfície de cerca de 15 por $10 \mathrm{~km}$, perfazendo $150 \mathrm{~km}^{2}$ distribuídos entre os municípios de Piraí do Sul, Tibagi e Castro. Dentro desta área deverão ser realizados estudos detalhados para indicar a parcela mais adequada para a futura criação da unidade de conservação. As principais particularidades de diversas ordens e naturezas que favorecem a preservação de características naturais nessa região são: 


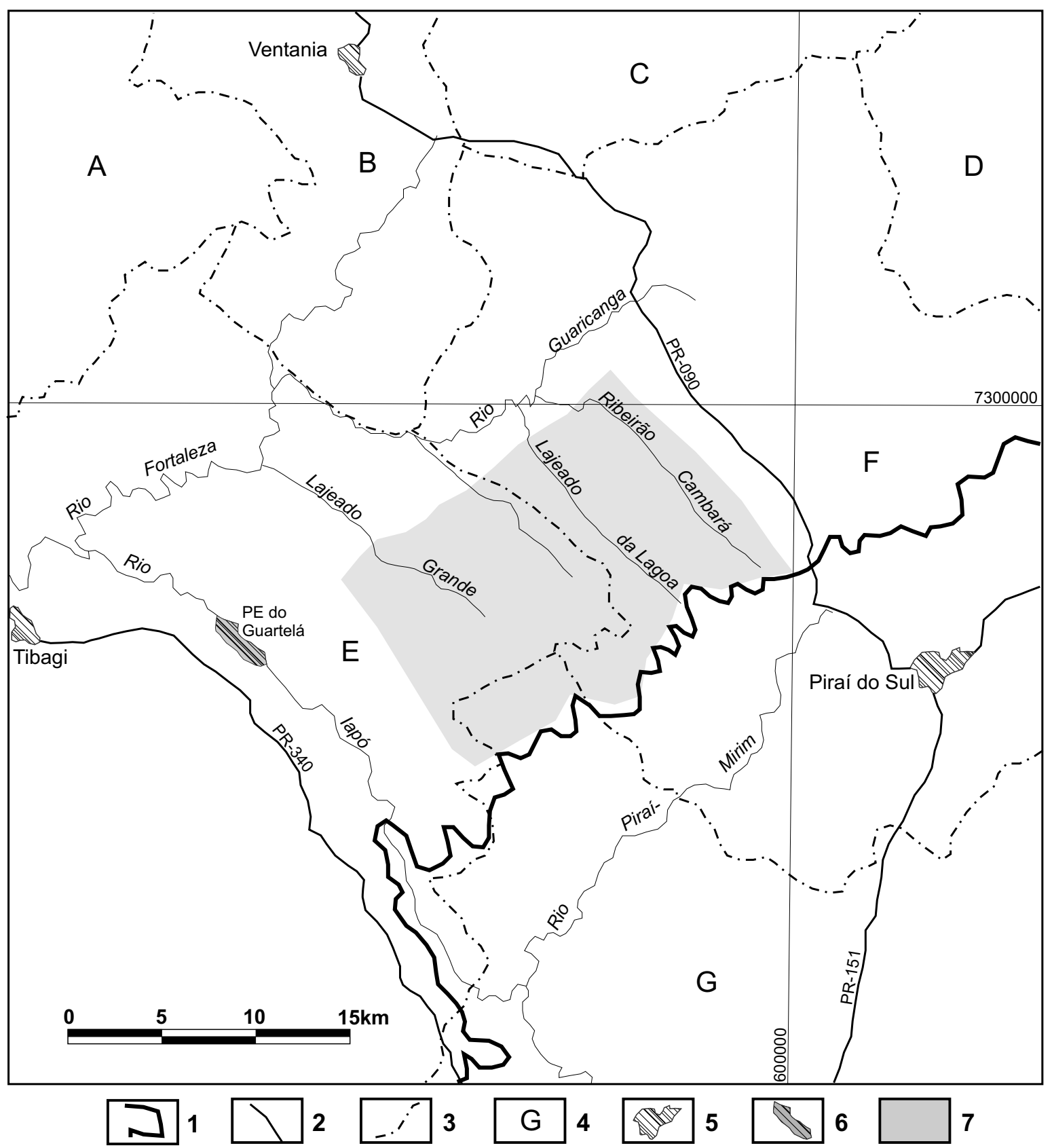

Figura 2 - A área preservada de Piraí da Serra. 1) Escarpa Devoniana; 2) Estradas principais; 3) Limites intermunicipais; 4) Municípios: A - Telêmaco Borba; B - Ventania; C - Arapoti; D - Jaguariaíva; E - Tibagi; F - Piraí do Sul; G - Castro; 5) Cidades; 6) Parque Estadual do Guartelá; 7) Principal área preservada de Piraí da Serra proposta para estudos de detalhe.

a) a região situa-se próximo ao Canyon do Guartelá, sobre o eixo do arqueamento crustal representado pelo Arco de Ponta Grossa; nessa região manifesta-se um dos mais notáveis enxames de diques da superfície do planeta, orientados paralelamente ao eixo do arqueamento, na direção NW-SE. Esses diques, constituídos de diabásio, microdiorito, quartzo- microdiorito e microdiorito pórfiro (Trein et al. 1966), também são rochas que originam solos férteis, propícios para desenvolvimento de vegetação arbórea (floresta de araucária), a qual por sua vez sustenta rica fauna. Os diques formam muitos canyons alongados na direção NW-SE, como o do Arroio Palmeirinha, paralelos ao Guartelá, que encaixam os tributários da 
margem esquerda do Rio Fortaleza. Cachoeiras e corredeiras são comuns;

b) essa topografia segmentada por canyons paralelos dificultou a expansão para a região dos latifúndios com agricultura mecanizada. Lá ainda existe estrutura tradicional de minifúndios familiares, com pecuária e agricultura de subsistência predominando sobre as grandes fazendas.

Em Piraí da Serra existem relevos ruiniformes, belíssimas cachoeiras e corredeiras, canyons, fendas, remanescentes de matas, campos e fauna nativos, e muitos sítios arqueológicos. É uma paisagem notável. As narrativas, mitos e lendas da população local, ainda muito tradicional, descendente dos antigos tropeiros, e com muitas histórias, envolvendo personagens, fatos, mitos e animais, também constitui característica marcante dessa região. A necessidade de preservação é ainda reforçada pela proximidade do Parque Estadual do Guartelá e da RPPN Estadual Itá-Y-Tyba. Destaque-se ainda que a área da margem esquerda do Rio Fortaleza é adjacente à região da Serra do Monte Negro, outra área pouco impactada nos Campos Gerais, recomendada para estudos de detalhamento.

\section{Síntese e discussão dos resultados}

Os resultados dos levantamentos realizados permitem tecer as seguintes considerações:

a) a região dos Campos Gerais é marcada por paisagens únicas e diversificadas, com presença da Escarpa Devoniana, extensas exposições de rochas e fósseis paleozóicos (formações Iapó, Furnas, Ponta Grossa e Grupo Itararé), formas de relevo muito características (canyons, furnas, relevos ruiniformes, lagoas e depressões, etc.), formações vegetais variadas (campos, floresta de araucária, floresta estacional, cerrado), rica fauna com muitas espécies endêmicas e/ou consideradas ameaçadas em outras áreas;

b) apesar de sua riqueza em paisagens únicas pela combinação de fatores abióticos e bióticos singulares, a região é ainda muito pouco estudada; faltam pesquisas que a caracterizem adequadamente em todos os campos de conhecimento;

c) as unidades de conservação já implantadas na região correspondem a somente $0,4 \%$ de seu território, o que é insuficiente para garantir a preservação de seu patrimônio natural;

d) a população local desconhece o patrimônio natural e arqueológico da região; as atividades de Educação Ambiental voltam-se na maior parte das vezes para atividades propostas pela mídia ou por programas universais, distantes da realidade local; o desconhecimento enfraquece a construção da identidade e da auto-estima da população, e prejudica iniciativas para proteção do patrimônio natural e arqueológico;

e) apesar do engajamento dos municípios dos Campos Gerais no antigo Plano Nacional da Municipalização do Turismo, ainda são precárias a compreensão e aceitação da vocação regional para o turismo em áreas naturais, com as implicações que isto traz para a escolha das diretrizes que orientem para o turismo sustentado;

f) o turismo em áreas naturais ainda é muito pouco organizado e explorado, apesar da antiguidade e notoriedade de algumas unidades de conservação, como os parques estaduais de Vila Velha e do Guartelá;

g) o desenvolvimento em bases sustentáveis do turismo em áreas naturais é favorecido pela localização geográfica e infra-estrutura privilegiadas, o que poderia trazer uma significativa fonte de riquezas e novos empregos;

h) o patrimônio natural da região encontra-se sob séria ameaça, por várias atividades econômicas de alto impacto ambiental, destacando-se a expansão dos florestamentos com espécies exóticas (Pinus), da agricultura intensiva (soja, trigo, milho) e da pecuária (suínos, aves, bovinos), que avançam rápida e indiscriminadamente sobre áreas com rico patrimônio natural e/ou arqueológico; outras atividades com forte impacto são o uso sistemático de queimadas, as atividades minerárias e a construção de usinas hidrelétricas.

Estes resultados conduzem a algumas discussões. Primeiramente, a necessidade de interdisciplinaridade na análise dos componentes do ambiente natural, desde os fatores abióticos (rochas, fósseis, relevo, hidrografia), passando pela bio-diversidade (flora, fauna), e alcançando os aspectos culturais, desde o patrimônio arqueológico até as tradições folclóricas e história oral das populações locais. 
Um outro aspecto a ser ressaltado é o fato de existirem áreas com importância relativa distinta entre fatores abióticos, bióticos e culturais. Na região dos Campos Gerais existem sítios já notórios que ora apresentam maior importância pelos fatores abióticos (v.g. Parque Estadual de Vila Velha), ora pelos fatores bióticos (v.g. Parque Estadual do Cerrado), ora pela conjugação de vários fatores (v.g. Parque Estadual do Guartelá). É necessário que a compreensão da importância relativa dos fatores conduza à consciência da vocação de cada área, que deverá orientar para seu adequado manejo.

\section{Conclusões}

Os Campos Gerais do Paraná constituem uma região muito rica em um patrimônio natural que encerra singulares exposições de rochas, jazigos fossilíferos e relevos de exceção, que ensejam a coexistência de diversas formações vegetais (campos, floresta de araucária, floresta estacional, cerrado) e fauna com diversas espécies em outros locais ameaçadas de extinção. Associado a este patrimônio natural ocorre significativo patrimônio arqueológico, representado por sítios em abrigos naturais que têm estreita relação com certos tipos de rochas e feições de relevo.

Este patrimônio natural e arqueológico constitui uma possibilidade notável para o desenvolvimento de pesquisas científicas, atividades de Educação Ambiental e turismo ecológico, com potencial para geração de riqueza e empregos em bases sustentáveis.

Entretanto, a região ainda é muito pouco estudada, as áreas protegidas somam somente $0,41 \%$ de seu território, e existe forte risco de degradação, representado principalmente pela expansão de florestamentos com espécies exóticas, agricultura e pecuária intensivas e uso sistemático de queimadas.

Neste contexto, a região de Piraí da Serra constitui-se em área prioritária para implantação de nova unidade de conservação, por reunir rico patrimônio natural preservado, por apresentar estrutura fundiária tradicional, que deverá favorecer negociações para desapropriações, e por situar-se em posição geográfica que favorece a inserção em corredores ecológicos que a integrem a outras unidades já implantadas.

\section{Agradecimentos}

São devidos aos pesquisadores de outras instituições que atuaram como consultores em áreas temáticas dos estudos (Cláudia Inês Parellada, Paulo César Fonseca Giannini), a diversos estagiários e bolsistas que participaram do desenvolvimento das pesquisas na região dos Campos Gerais (Adriana Micheli, Alcileia Jakeline Felix da Silva, Alessandro Giulliano Chagas Silva, Andreia da Cruz, Andréia Rolim Delgado, Angelo dos Santos, Átila Cristian Santana, Cibele Maria Vianna Zanon, Daniela Corrêa da Maia, Elynton Alves do Nascimento, Karin Vangela De Geus, Karine Krunn, Larissa Estreiechen, Lia Maris Ritter, Michele Engels, Pablo Rodigheri Melek, Priscila Sirigate, Sabrina Ghiraldelli) e às instituições que direta ou indiretamente deram suporte à realização dos estudos (Fundação Araucária, CNPq - Plano Sul de Pesquisa e Pós-Graduação, Prefeitura Municipal de Tibagi).

\section{REFERÊNCIAS}

1. DGTC - Departamento de Geografia, Terras e Colonização do Estado do Paraná. Levantamento aerofotogramétrico 1:70.000 do Estado do Paraná. Curitiba, DGTC (órgão incorporado pela atual Secretaria de Estado do Meio Ambiente - SEMA). 1962/1963.

2. EMBRAPA - Empresa Brasileira de Pesquisa Agropecuária. Mapa pedológico do Estado do Paraná - arquivo digital. Rio de Janeiro, CNS/EMBRAPA. CD-ROM. 2002.

3. ESRI. ArcView GIS The geographic Information System for Everyone. Redlands: Environmental Systems Research Institute, 2000, 350p.

4. IAPAR - Instituto Agronômico do Paraná. Cartas Climáticas do Estado do Paraná. Londrina, IAPAR Ed., 45p. 1994.

5. IAPAR - Instituto Agronômico do Paraná. Cartas climáticas do Estado do Paraná. Londrina: IAPAR, 1 CD-ROM. Versão 1.0. 2000 .

6. IBGE - Instituto Brasileiro de Geografia e Estatística. Manual Técnico da Vegetação Brasileira. Rio de Janeiro, IBGE. (Série Manuais Técnicos em Geociências, 1). 1992. 92p.

7. IBGE - Instituto Brasileiro de Geografia e Estatística. Base de Informações Muncipais [CD-ROM]. Rio de Janeiro. 2000. 
8. ITC - PR - Instituto de Terras e Colonização do Estado do Paraná. Levantamento aerofotogramétrico do Estado do Paraná em escala 1:25.000. Curitiba, Aerosul. 1980.

9. MAACK, R. Mapa fitogeográfico do Estado do Paraná. Curitiba: Inst. Biol. Pesq. Tecnol. e Inst. Nac. Pinho. 1950.

10. MELO, M.S. Controle estrutural e litológico da erosão subterrânea e superficial de arenitos da região dos Campos Gerais do Paraná. IGc-USP, Relatório de pesquisa de pósdoutorado, 2004. 61p.

11. MELO, M.S.; GUIMARÃES, G.B.; MELEK, P.R.; SANTANA, Á.C.; SILVA, A.G.C. Geologia e Geomorfologia dos Campos Gerais do Paraná. In: SIMPÓSIO DE ROTEIROS GEOLÓGICOS DO PARANÁ, 1, Ponta Grossa, 2002. Guia... Ponta Grossa, UEPG/SBG-PR, 2002. p.5-14.

12. MELO, M.S.; GODOY, L.C.; MENEGUZZO, P.M.; SILVA, D.J.P. A Geologia no plano de manejo do Parque Estadual de Vila Velha, PR. Rev. Bras. Geoc. v.34, n.4, p.561-570, 2004.

13. MINEROPAR - Minerais do Paraná S/A. Mapa geológico do Estado do Paraná, escala 1:1.000.000 (meio digital). Curitiba, MINEROPAR, CD-ROM. 2001.

14. MORO, P.R. A Educação Ambiental e a formação do professor. Ponta Grossa, 2002. 98p. Dissertação (Mestrado em)-UEPG.

15. MORO, R.S. A vegetação dos Campos Gerais da escarpa devoniana. In: DITZEL, C.H.M.; SAHR, C.L.L. Espaço e cultura: Ponta Grossa e os Campos Gerais. Editora da UEPG, 2001. p.481503.

16. MORO, R.S.; RITTER, L.M.O.; ESTREIECHEN, L.
Comunidades pioneiras dos afloramentos rochosos da Escarpa Devoniana, Campos Gerais, PR. In: $53^{\circ}$ Congresso Nacional de Botânica e $25^{\circ}$ Reunião Nordestina de Botânicae. Livro de Resumos. Recife: SBB/ UFRPE, v.1. 2002.

17. NASCIMENTO, E.A.; MICHELI, A.; BARBOLA, I.F. Inventário da entomofauna dos sítios naturais dos Campos Gerais do Paraná, Brasil. XXIV Congresso Brasileiro de Zoologia, Itajaí, 17-22 fev. (Livro de Resumos). 2002.

18. SILVA, A.G.C.; MELO, M.S. Pinturas rupestres em abrigo sob rocha no Rio Quebra-Perna, Ponta Grossa, Paraná. In: DITZEL, C. H. M. \& SAHR, C.L.L. (Eds.), Ponta Grossa e os Campos Gerais: estudos de Geografia e História Regional. Ponta Grossa, Editor UEPG, v.2, p. (aceito). 2002.

19. SILVA, A.G.C.; PARELLADA, C.I.; MELO, M.S. Pinturas rupestres do sítio arqueológico Abrigo Usina São Jorge, Ponta Grossa, PR. Curitiba, Arquivos do Museu Paranaense, n.9 (nova Série Arqueologia) (aceito, no prelo). 2001.

20. SOBREVILLA, C.; BATH, P. Evaluación ecológica rápida: un manual para usuários de América Latina y el Caribe. Washington: The Nature Conservancy, 1992.

21. TREIN, E.; FUCK, R.A.; LOPES, J.A. ; MURATORI, A. ; PALKA, J. Folha geológica de Colônia Iapó, escala 1:50.000. Curitiba, Comissão da Carta Geológica do Paraná. 1966.

22. UEPG - Universidade Estadual de Ponta Grossa. Caracterização do patrimônio natural dos Campos Gerais do Paraná. Relatório de Pesquisa. Ponta Grossa: UEPG 2003, 239p.

23. VELOSO, H.P.; RANGEL FILHO, A.L.R.; LIMA, J.C.A. Classificação da vegetação brasileira, adaptada a um sistema universal. Rio de Janeiro: IBGE, 1991. 123 p. 